\title{
PENGARUH KADAR IMPURITIS PADA MOLTEN ALUMINIUM TERHADAP STANDAR GRADE ALUMINIUM (SGA) DI STASIUN HPM CENTRE PT INALUM (PERSERO) - KUALA TANJUNG
}

\author{
Anton Sudiyanto ${ }^{1}$, Intan Maharani ${ }^{2}$ dan Muhamad Alfa Rizky ${ }^{3}$ \\ 1,2,3 Prodi Teknik Metalurgi, Jurusan Teknik Pertambangan, Fakultas Teknologi Mineral, \\ UPN "Veteran" Yogyakarta, Jl. Babarsari 2, Tambakbayan, Depok, Sleman, Yogyakarta, 55281 \\ E-mail: anton.sudiyanto@ upnyk.ac.id ${ }^{1}$, intanmharani31@ gmail.com $^{2}$; rizkyalfa62@ gmail.com ${ }^{3}$ \\ (+62 812-1651-8728, +62 822-2342-0062)
}

\begin{abstract}
One of the suppliers of aluminum needs in the world and in Indonesia is PT INALUM (Persero) with a production capacity of 260,000 tons per year. The aluminum products manufactured by PT INALUM (Persero) consist of bars, alloys and billets with different degrees of purity. Apart from these 3 products, however, there are other products that also have a higher sales value, namely S1-B products. In the aluminum smelting process, it is certain that $100 \%$ pure aluminum cannot be produced; the result is impurities. In this case, the more closely observed impurities are silicon ( $\mathrm{Si}$ ) and iron (Fe). PT INALUM offers several standards for the purity of aluminum. The compositional test aims to determine the level of impurities in the aluminum sample. This test was carried out with OES (Optical Emission Spectrophotometer). This test begins by taking a sample of the Test Product Metal (TPM) from molten aluminum, then cooling the sample and then sending it to Smelter Quality Assurance (SQA) to determine the purity and impurity levels. Based on the results of the analysis, the malleable aluminum is grade S1-A with an aluminum content of $99.92 \%$ and S1-B with an aluminum content of $99.90 \%$. For example, the batch number 210520 must be printed with a purity of $99.92 \%$ for type S1-A. In the meantime, batch number 210536 with $99.91 \%$ aluminum purity cannot be printed for grade S1-A. Because when printing for type S1-A there are still impurities in it and for type G1 the purity is still too high. Therefore it is necessary to make adjustments to the given grade.
\end{abstract}

Keyword : HPM Centre Station, Ingot, Impurities and Standar Grade Aluminium

\begin{abstract}
Abstrak
Salah satu pemasok kebutuhan aluminium dunia dan Indonesia adalah PT INALUM (Persero) dengan kapasitas produksi masih sebesar 260.000 ton per tahun. Produk aluminium yang dihasilkan pada PT INALUM (Persero) terdiri dari ingot, alloy dan billet dengan tingkat kemurnian yang berbeda. Namun selain 3 produk tersebut ada produk lain yang juga memiliki nilai jual lebih tinggi, yaitu produk S1-B. Dalam proses peleburan aluminium pastilah tidak dapat dihasilkan aluminium yang $100 \%$ murni, terdapat zat pengotor didalam hasilnya. Dalam hal ini, zat pengotor yang lebih dicermati adalah silikon ( $\mathrm{Si}$ ) dan besi (Fe). PT INALUM memberikan beberapa standar terhadap kemurnian dari aluminium. Pengujian komposisi bertujuan untuk mengetahui kadar pengotor yang terkandung pada sample aluminium. Pengujian ini dilakukan menggunakan OES (Optical Emission Spectrofotometer). Pengujian ini dimulai dari pengambilan sample Test Product Metal (TPM) aluminium cair, kemudian sample tersebut didinginkan dan setelah itu sample dikirim ke bagian Smelter Quality Assurance (SQA) untuk mengetahui kemurnian dan kandungan zat pengotornya. Berdasarkan hasil analisis, aluminium yang memungkinkan dicetak adalah grade S1-A dengan kadar aluminium 99,92\% dan S1-B dengan kadar aluminium $99,90 \%$. Sebagai contoh untuk nomor lot 210520 dengan kemurnian 99,92\% harus dicetak untuk grade S1-A. Sementara lot nomor 210536 dengan kemurnian aluminium 99,91\% tidaklah memungkinkan dicetak untuk grade S1-A. Karena apabila dicetak untuk grade S1-A, masih terdapat zat pengotor didalamnya dan untuk grade G1 pun masih terlalu tinggi kemurniannya. Oleh sebab itu, perlu dilakukan penyesuaian terhadap grade yang ditentukan. Kata kunci: Stasiun Pusat HPM, Ingot, Pengotor dan Standar Grade Aluminium (SGA).
\end{abstract}


Journal Of Metallurgical Engineering And Processing Technology, Vol. 2, No. 1, February 2022, pp. 1-10

P-ISSN: 2723-6854, E-ISSN: 2798-1037

\section{Pendahuluan}

Alumunium merupakan salah satu logam yang banyak digunakan di dunia selain baja. Alumunium hadir di kehidupan kita sehari hari berupa perabotan rumah tangga, kaleng minuman, bahan konstruksi, hingga ke bahan bahan medis. Untuk memenuhi kebutuhan khalayak manusia, maka diproduksilah aluminium secara masal. Alumunium diproduksi secara komersial menggunakan Proses Hall-Heroult. Ini adalah proses elektrokimia dalam aluminium yang direduksi dari alumina kemudian dilarutkan dalam elektrolit garam cair berbasis cryolite (bath). Selsel reduksi dihubungkan secara seri di bawah arus listrik yang relatif tinggi.

Kebutuhan akan aluminium tersebut meningkat setiap tahunnya dengan kebutuhan dunia tercatat berkembang sebesar 29 juta ton per tahun, sementara Indonesia memiliki kebutuhan aluminium sebesar 200.000-300.000 per tahun. Salah satu pemasok kebutuhan aluminium dunia dan Indonesia adalah PT INALUM (Persero) dengan kapasitas produksi masih sebesar 260.000 ton per tahun. Produk aluminium yang dihasilkan pada PT INALUM (Persero) terdiri dari ingot, alloy dan billet dengan tingkat kemurnian yang berbeda. Produk yang memiliki nilai kemurnian yang tinggi atau memiliki impuritis dalam jumlah yang rendah disebut dengan high purity metal (HPM).

Produk S1B (ingot) termasuk salah satu produk dari pot high purity metal (HPM). Selain itu, pot HPM ini juga dapat menghasilkan produk alloy.
Dimana $\mathrm{Fe}$ untuk produk alloy cenderung lebih rendah. Target yang ditetapkan untuk jumlah pot HPM di tahun 2020 adalah sebesar 85 pot. Strategi yang digunakan untuk mendapatkan target tersebut adalah dengan melakukan pembuatan stasiun HPM Centre.

Pada proses pengolahannya, PT INALUM memiliki 6 stasiun yang terbagi menjadi stasiun HPM Centre dan stasiun Non HPM Centre. stasiun HPM Centre terdiri dari stasiun 2, stasiun 4 dan stasiun 5 , sedangkan pada stasiun 1 , stasiun 3 dan stasiun 6 merupakan stasiun Non HPM Centre. Secara teori, pot pada stasiun HPM Centre akan menghasilkan jumlah pot HPM yang lebih banyak dibandingkan dengan stasiun Non HPM Centre.

Kualitas metal merupakan parameter penting untuk meningkatkan produksi agar dapat bersaing dalam dunia industri. Salah satu faktor yang dapat menurunkan kualitas ataupun kemurnian metal adalah impuritis yang ada didalam metal. Impuritis tersebut dapat dikurangi pada bagian katoda, anoda, dan berakhir di metal. Adapun jenis impuritis yang sering terkandung didalam aluminium adalah $\mathrm{Fe}, \mathrm{Si}, \mathrm{Cu}, \mathrm{Na}, \mathrm{Ti}, \mathrm{Mn}, \mathrm{Mg}$ dan sebagainya. (Al-Mejali dkk., 2016).

Impuritis yang menjadi perhatian dalam analisa ini adalah besi ( $\mathrm{Fe}$ ) dan silikon (Si). Impuritis tersebut dapat berasal dari parameter operasi seperti ketinggian bath, keasaman, dan lainnya. Adanya zat pengotor tersebut akan mempengaruhi kualitas dari aluminium yang dihasilkan, sehingga PT INALUM menetapkan 
Journal Of Metallurgical Engineering And Processing Technology, Vol. 2, No. 1, February 2022, pp. 1-10

P-ISSN: 2723-6854, E-ISSN: 2798-1037

standar terhadap kemurnian dari aluminium. Untuk mengurangi kelebihan atau menyeimbangkan kadar zat pengotor yang terdapat dalam aluminium yaitu dengan cara pemberian aluminium murni.

Aluminium mempunyai titik lebur $2000^{\circ} \mathrm{C}$, namun dengan proses elektrolisa metode Hall Heroult yang menggunakan cryolite $\left(\mathrm{Na}_{3} \mathrm{AlF}_{6}\right)$, aluminium dapat diperoleh pada temperatur $1000^{\circ} \mathrm{C}$, dan dengan memasukkan zat additif seperti $\mathrm{AlF}_{3}$, $\mathrm{CaF}_{2}$ dan bahan-bahan lain yang terdapat didalam bahan baku, maka aluminium dapat diperoleh pada temperatur $960^{\circ} \mathrm{C}$ sampai $970^{\circ} \mathrm{C}$. Adapun aluminium yang dihasilkan adalah aluminium yang berbentuk batangan (ingot) dengan berat perbatangnya $22,7 \mathrm{~kg}$.

Bahan Baku untuk memproduksi aluminium memerlukan bahan sebagai berikut :

\section{A. Bahan baku utama}

\section{Alumina}

Alumina diperoleh dari bauksit melalui beberapa proses Bayer. Bauksit merupakan bahan baku $\mathrm{Al}$ yang terdiri dari $\mathrm{Al}_{2} \mathrm{O}_{3}$ (aluminium oksida) dan memiliki kemurnian yang berbeda seperti besi oksida, aluminium silica dan titanium oksida. Aluminium oksida $\left(\mathrm{Al}_{2} \mathrm{O}_{3}\right)$ atau alumina biasanya berupa kristal ion. Tetapi ion oksida $\left(\mathrm{O}_{2}{ }^{-}\right)$ dipolarosasi oleh ion aluminium sehingga sebagian ikatannya bersifat kovalen. Aluminium oksida meleleh pada $2035^{\circ} \mathrm{C}$. Berikut reaksi pembentukan ion $\mathrm{Al}$ dari Alumina, yaitu;
$\mathrm{Al}_{2} \mathrm{O}_{3(\mathrm{~s})}+6 \mathrm{H}^{+}{ }_{(\mathrm{aq})} \rightarrow 2 \mathrm{Al}^{3+}{ }_{(\mathrm{aq})}+3 \mathrm{H}_{2} \mathrm{O}_{(\mathrm{l})}$ atau

$\mathrm{Al}_{2} \mathrm{O}_{3(\mathrm{~s})}+2 \mathrm{OH}_{(\mathrm{aq})}^{-}+3 \mathrm{H}_{2} \mathrm{O} \rightarrow 2 \mathrm{Al}(\mathrm{OH})_{4}^{-}$

Bauksit merupakan bijih utama aluminium terdiri dari hydrous aluminium oksida dan aluminium hidroksida yakni dari mineral gibbsite $\mathrm{Al}(\mathrm{OH})_{3}$, boehmite $\gamma$-ALO $(\mathrm{OH})$, dan diaspore $\alpha-\mathrm{ALO}(\mathrm{OH})$, bersama-sama dengan oksida besi goethite dan bijih besi, mineral tanah liat kaolinit dan sejumlah kecil anatase $\mathrm{TiO}_{2}$. Alumina diperoleh dari bauksit melalui proses bayer, alumina yang diperoleh dari proses bayer ini mempunyai kemurnian yang tinggi dan dengan konsumsi energi yang rendah.

Proses pengolahan alumina dari bauksit dengan proses bayer. Proses ini merupakan proses pelindian Bauksit yang direaksikan dengan $\mathrm{NaOH}$ dalam reaktor silindris tegak bertekanan dan bertemperatur tinggi atau biasa disebut tangki Digester. Pelindian ini akan menghasilkan larutan Sodium Aluminate $\left(\mathrm{Na}\left[\mathrm{Al}(\mathrm{OH})_{4}\right]\right)$ dan pengotor yang tidak ikut larut dalam larutan.

Berikut reaksi pelindian nya pada proses Bayer, sebagai berikut :

$\mathrm{Al}_{2} \mathrm{O}_{3} \cdot \mathrm{xH}_{2} \mathrm{O}+2 \mathrm{NaOH} \rightarrow 2 \mathrm{NaAlO}_{2}+(\mathrm{x}$ +1) $\mathrm{H}_{2} \mathrm{O}$

Langkah akhir dari proses Bayer adalah kalsinasi presipitat hasil proses presipitasi. Kalsinasi sendiri adalah proses pemanasan presipitat dengan suhu dibawah temperatur lelehnya dalam kondisi kecukupan oksigen dimana proses ini bertujuan untuk menghilangkan air kristal pada 
Journal Of Metallurgical Engineering And Processing Technology, Vol. 2, No. 1, February 2022, pp. 1-10

P-ISSN: 2723-6854, E-ISSN: 2798-1037

presipitat. Dalam kalsinasi presipitat aluminium hydrate, reaksi yang terjadi adalah sebagai berikut:

$2 \mathrm{NaAlO}_{2}+4 \mathrm{H}_{2} \mathrm{O}+$ kalor $\rightarrow \mathrm{Al}_{2} \mathrm{O}_{3}+3$ $\mathrm{H}_{2} \mathrm{O}$; suhu $(1050-1350)^{\circ} \mathrm{C}$.

Akan tetapi, PT. INALUM tidak menghasilkan alumina sendiri tetapi diperoleh dari negara lain terutama dari negara Australia. Spesifikasi alumina yang diperlukan untuk peleburan aluminium ditunjukkan pada tabel 1 dibawah ini.

Tabel 1. Spesifikasi Alumina

\begin{tabular}{|c|c|c|c|}
\hline No. & PARAMETERS & UNIT & $\begin{array}{c}\text { SPESIFIKASI } \\
\text { Grade - } 1\end{array}$ \\
\hline 1. & Loss of Ignition (LOI) $300-1000^{\circ} \mathrm{C}$ & $\%$ & $1.0 \max$ \\
\hline 2. & $\mathrm{SiO}_{2}$ & $\%$ & $0.030 \max$ \\
\hline 3. & $\mathrm{Fe}_{2} \mathrm{O}_{3}$ & $\%$ & $0.030 \max$ \\
\hline 4. & $\mathrm{TiO}_{2}$ & $\%$ & $0.005 \max$ \\
\hline 5. & $\mathrm{Na}_{2} \mathrm{O}$ & $\%$ & $0.600 \max$ \\
\hline 6. & $\mathrm{CaO}$ & $\%$ & $0.060 \max$ \\
\hline 7. & $\mathrm{~V}_{2} \mathrm{O}_{5}$ & $\%$ & $0.005 \max$ \\
\hline 8. & $\mathrm{P}_{2} \mathrm{O}_{5}$ & $\%$ & $0.003 \max$ \\
\hline 9. & $\mathrm{ZnO}$ & $\%$ & $0.016 \max$ \\
\hline 10. & $\mathrm{Al}_{2} \mathrm{O}_{3}$ (on dried basis) & $\%$ & $98.4 \mathrm{~min}$ \\
\hline \multirow[t]{3}{*}{11.} & Moisture on Impact (MOI) $300^{\circ} \mathrm{C}$ & $\%$ & \\
\hline & a. Sampling at Supplier & $\%$ & $1.7 \max$ \\
\hline & b. Sampling at INALUM & $\%$ & $3.5 \max$ \\
\hline 12. & Spesific Surface Area & $\mathrm{m}^{2} / \mathrm{g}$ & $40-85$ \\
\hline \multirow[t]{4}{*}{13.} & Particle Size & $\%$ & \\
\hline & a. +100 mesh & $\%$ & $8 \max$ \\
\hline & b. +150 mesh & $\%$ & $20 \min$ \\
\hline & c. -325 mesh & $\%$ & $12 \max$ \\
\hline 14. & Angle of repose & deg & $30-34$ \\
\hline
\end{tabular}

Sumber : SRP PT INALUM (2021)

\section{Anoda}

Anoda adalah elektroda bermuatan listrik positif. Jenis anoda yang dipakai adalah jenis anoda prebaked, anoda yang digunakan di seksi reduksi dibuat di gedung karbon dengan bahan kokas dan hard pitch.

\section{Katoda}

Katoda adalah elektroda bermuatan listrik negatif. Ditinjau dari bahan bakunya dan prose pembuatannya, katoda dibagi atas 4 jenis, yaitu :

a. Blok katoda Amorphous, bahan bakunya antrasit, dipanggang pada suhu $\pm 1.200^{\circ} \mathrm{C}$

b. Blok katoda semi graphitic, bahan bakunya grafit, dipanggang pada suhu $\pm 1.200^{\circ} \mathrm{C}$

c. Blok katoda semi graphitic, bahan bakunya yang mengalami proses pemanasan sampai suhu $\pm 2.300^{\circ} \mathrm{C}$

d. Blok katoda graphitic, bahan bakunya kokas mengalami proses grafitasi suhu $\pm 3.000^{\circ} \mathrm{C}$

B. Bahan Baku Penunjang

1. Cryolite

Cryolite dapat mengandung $\mathrm{CaF}_{2}$ dan $\mathrm{AlF}_{3}$ yang dapat membentuk cryolite $\mathrm{Na}_{3} \mathrm{AlF}_{6}$. Sifat-sifat cryolite adalah :

a. Konduktivitas listrik baik.

b. Memiliki berat jenis yang rendah.

c. Temperatur kristalisasi primer rendah.

d. Stabil dalam keadaan cair.

e. Dapat melarutkan alumina dalam jumlah besar.

Untuk memperbaiki sifat-sifat cryolite tersebut, bath biasanya ditambah dengan beberapa bahan tambahan seperti fluorida, alkil metal, $\mathrm{AlF}_{3}$ dan $\mathrm{CaF}_{2}$.

\section{Soda $\mathrm{Abu}\left(\mathrm{Na}_{2} \mathrm{CO}_{3}\right)$}

Soda abu berfungsi memperkuat struktur katoda dan dinding samping agar sulit 
Journal Of Metallurgical Engineering And Processing Technology, Vol. 2, No. 1, February 2022, pp. 1-10

P-ISSN: 2723-6854, E-ISSN: 2798-1037

tererosi. Lapisan dinding samping dengan $\mathrm{Na}_{2} \mathrm{CO}_{3}$ dilakukan pada tahap transisi untuk membantu proses pembentukan kerak samping. Selain mencegah erosi oleh bath, soda abu berfungsi sebagai isolasi termal.

\section{Aluminium Florida $\left(\mathrm{AlF}_{3}\right)$}

Aluminium florida berfungsi menjaga keasaman bath dan merupakan bahan yang dituangkan secara manual jika kelebihan $\mathrm{AlF}_{3}$ kurang didalam bath.

Spesifikasi $\mathrm{AlF}_{3}$ yang digunakan oleh $\mathrm{PT}$ INALUM dicantumkan pada tabel berikut.

Tabel 2. Spesifikasi $\mathrm{AlF}_{3}$

\begin{tabular}{|l|c|c|}
\hline \multicolumn{1}{|c|}{ Jenis } & Unit & Spesifikasi \\
\hline $\mathrm{AlF}_{3}$ & $\%$ & 93 minimal \\
\hline $\mathrm{SiO}_{2}$ & $\%$ & 0,25 maksimal \\
\hline $\mathrm{P}_{2} \mathrm{O}_{5}$ & $\%$ & 0,02 maksimal \\
\hline $\mathrm{Fe}_{2} \mathrm{O}_{3}$ & $\%$ & 0,07 maksimal \\
\hline Moisture (Water Content) & $\%$ & 0,35 maksimal \\
\hline Loss on Ignitation $300-1000^{\circ} \mathrm{C}$ & $\%$ & 0,85 maksimal \\
\hline Bulk density & & 0,7 minimal \\
\hline Particle Size (Tyler Mesh) & & Typical \\
\hline+150 mesh & $\%$ & $25-60$ \\
\hline+200 mesh & & $50-75$ \\
\hline+320 mesh & & \\
\hline
\end{tabular}

Sumber : SRP PT INALUM (2021)

High Purity Metal (HPM) merupakan metal yang memiliki kemurnian yang tinggi atau memiliki kadar impuritis dalam jumlah yang sedikit. Aluminium dengan kemurnian tinggi (High Purity Aluminium) bersifat tahan korosi, ringan, mudah dibentuk, dan memiliki kondutivitas termal dan listrik yang baik.

Oleh karena itu, dalam beberapa tahun terakhir teknik telah dikembangkan untuk menghasilkan beberapa jenis aluminium dengan tingkat kemurnian yang berbeda pada berbagai aplikasi. Hal ini sangat relevan pada industri semikonduktor, dimana aluminium dengan kemurnian tinggi digunakan untuk proses sputtering. Fenomena ini telah menyebabkan peningkatan besar dalam permintaan untuk aluminium dengan kemurnian tinggi. Namun, teknologi produksi aluminium dengan kemurnian tinggi belum meningkat secara signifikan dan masih banyak kendala dalam operasi produksi, biaya dan lingkungan. (Wan dkk., 2020).

\section{Material dan Metode Percobaan}

\section{A. Material}

1. Molten aluminium dengan kandungan :
a. Alumina $\left(\mathrm{Al}_{2} \mathrm{O}_{3}\right)$
b. Larutan bath $\left(\mathrm{Na}_{3} \mathrm{AlF}_{6}\right)$
c. $\mathrm{AlF}_{3}$
d. Impuritis (Fe dan $\mathrm{Si}$ )
2. De-inclusion flux

\section{B. Metode Percobaan}

1. Pengisian Aluminium Cair

a. Aluminium cair yang dibawa dari pabrik reduksi dituangkan kedalam dapur peleburan kemudian diberikan de-inclusion flux untuk mengangkat kotorankotoran di dalam aluminium.

b. Kemudian dilakukan skimming off untuk membersihkan kotoran- 
Journal Of Metallurgical Engineering And Processing Technology, Vol. 2, No. 1, February 2022, pp. 1-10

P-ISSN: 2723-6854, E-ISSN: 2798-1037

kotoran yang mengapung diatas permukaan aluminium cair.

2. Pengambilan Sampel Test Product Metal (TPM) Aluminium Cair

a. Pengambilan sampel test product metal dilakukan 30 menit sebelum pencetakan aluminium. Pengambilan sampel dilakukan melalui pintu samping dapur dengan menggunakan alat penciduk sampel yang diambil $1 / 2$ meter dari kedalaman aluminium cair didalam dapur.

b. Sampel aluminium yang diambil kemudian didinginkan diruangan terbuka hingga membeku. Setelah dingin, diberi nomor lot terhadap sampel.

c. Kemudian sampel dikirim ke bagian Smelter Quality Assurance (SQA) untuk mengetahui kemurnian dan kandungan zat pengotor, antara lain silikon ( $\mathrm{Si}$ ) dan besi $(\mathrm{Fe})$.

\section{Penganalisaan Produk}

a. Sampel yang didatangkan dari bagian casting terlebih dahulu dibubut, agar permukaan dari sampel rata, halus dan bersih.

b. Setelah dibubut, sampel dibawa ke ruang OES (Optical Emission Spectrofotometer).

c. Dibuka ruang eksitasi, lalu diletakkan sampel diatas meja eksitasi.

d. Kemudian pintu ruang eksitasi ditutup, lalu tekan tombol "enter" pada keyboard komputer, maka alat OES akan bekerja dengan sendirinya. Setelah emisi, maka nilai pengukuran sampel akan terlihat pada layar komputer.

e. Setelah selesai, buka kembali ruang eksitasi dan sampel dapat dikeluarkan dari ruang eksitasi.

f. Lakukan pengerjaan eksitasi sebanyak 3 kali pengerjaan pada setiap sampel

g. Dicatat hasil yang didapat dari percobaan yang dilakukan.

Adapun flowchart yang digunakan dalam penelitian ini adalah sebagai berikut ;

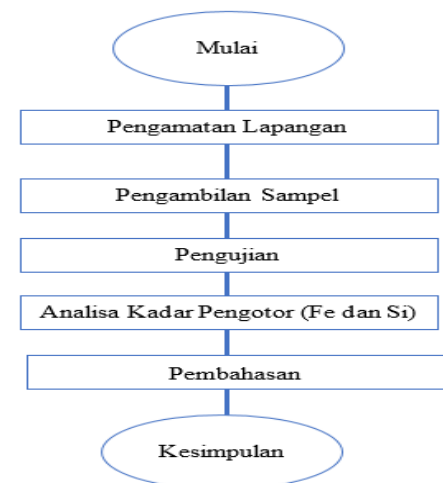

Gambar 1. Flowchart Penelitian

\section{Hasil Penelitian dan Pembahasan}

Tabel 3 merupakan hasil pengukuran dibeberapa pot (tungku reduksi), dari beberapa pot akan dilakukan Metal Tapping (pengambilan metal), lalu dicampur didalam gedung Smelter Casting (pencetakan). Pencampuran dilakukan berdasarkan kadar zat pengotornya, sehingga bisa sesuai standar yang ditetapkan di PT INALUM. Didalam gedung Smelter Casting terdapat dapur pencetakan yang berkapasitas 30 Ton. Dari gedung Smelter Casting akan diambil sampel, untuk dianalisa dibagian SQA sebelum akhirnya dicetak. 
Journal Of Metallurgical Engineering And Processing Technology, Vol. 2, No. 1, February 2022, pp. 1-10

P-ISSN: 2723-6854, E-ISSN: 2798-1037

Hasil pengukuran serta pengujian Gambar 2. Bath Sample Calibration dilakukan pada bagian SQA (Smelter Quality Assurance) di PT INALUM untuk menganalisis sampel yang telah diambil pada bagian SRO (Smelter Reduction Operation).

Berikut salah satu lembar kerja pada bagian SQA, pada Gambar 2, yaitu :

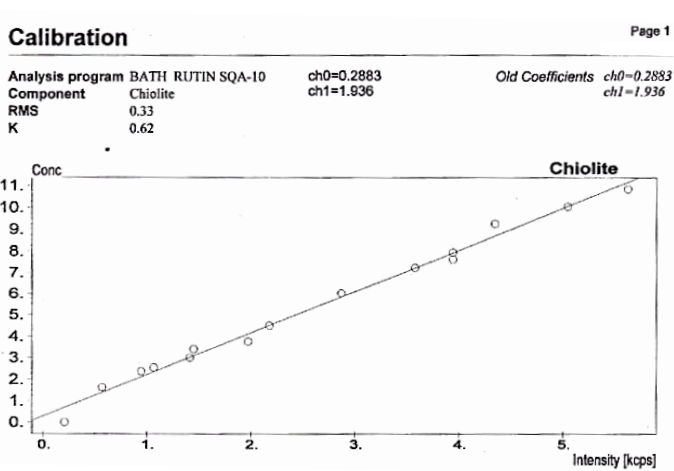

Sumber : SQA PT INALUM (2021)

Tabel 3. Pengukuran Kadar Fe dan Si di Stasiun 5

\begin{tabular}{|c|c|c|c|c|c|c|c|c|c|c|c|c|c|c|c|c|c|c|c|}
\hline \multicolumn{4}{|c|}{ 51/20.121 } & \multicolumn{4}{|c|}{ 52/2021 } & \multicolumn{4}{|c|}{ 53/2021 } & \multicolumn{4}{|c|}{ 5, 40.21} & \multicolumn{4}{|c|}{$5 / 502021$} \\
\hline PONNWY & UnmurPot & $\mathrm{Fe} \%$ & $\mathrm{Si} \%$ & POTNCM & $\operatorname{mir}^{\prime \prime P}$ & $\mathrm{Fe} \%$ & $\mathrm{Si} \%$ & POTNUY & Umur Pot & $\mathrm{Fe} \%$ & $\mathrm{Si} \%$ & POTNCY & Imurpot & $\mathrm{Fe} \%$ & Si\% & POTNOM & Unur Pot & $\mathrm{Fe} \%$ & Si\% \\
\hline 504 & 1601 & 0.0157 & 0.025 & 504 & $166 ?$ & 0.057 & 0.025 & $5 \mathrm{NH}$ & 1663 & 0.061 & 0,027 & 504 & 1664 & 0.061 & 0.027 & $5 \mathrm{NA}$ & 1665 & 0.049 & 0.027 \\
\hline 506 & 782 & 0.069 & 0.026 & 506 & 783 & 0.069 & 0.026 & 506 & 784 & 0.069 & 0,026 & 506 & $78{ }^{\circ}$ & 0.069 & 0,026 & 506 & 786 & 0.047 & 0.026 \\
\hline 509 & 1011 & 0.041 & 0.025 & 509 & 1012 & 0.041 & 0.025 & 50 & 1013 & 0.45 & 0,026 & 509 & 1014 & 0.045 & 0,026 & 509 & 1015 & 0.042 & 0,025 \\
\hline 517 & 798 & 0.065 & 0.026 & 517 & 799 & 0,065 & 0.026 & 517 & 760 & 0.06 & 0,026 & 517 & 761 & 0.016 & 0,026 & 517 & 762 & 0.0133 & 0.025 \\
\hline$\$ 21$ & 430 & 0.066 & 0.027 & 521 & 431 & 0.066 & 0.027 & 541 & 432 & 0.066 & 0.027 & 521 & 433 & 0.066 & 0.027 & 521 & 434 & 0.061 & 0.027 \\
\hline 523 & 813 & 0.049 & 0.025 & 523 & 814 & 0,04 & 0.0126 & 523 & 815 & 0.044 & 0,026 & 523 & 816 & 0.042 & 0.087 & 53 & 817 & 0,042 & 0.027 \\
\hline 526 & 1697 & 0.0155 & 0.026 & 526 & 1698 & $0,0.52$ & 0.027 & 526 & 1699 & 0.052 & 0.027 & 526 & 1700 & 0.054 & 0.027 & 526 & 1701 & 0,058 & 0.027 \\
\hline 529 & 363 & 0.053 & 0.026 & 529 & 364 & 0.061 & 0.027 & 529 & 365 & 0.061 & 0.027 & 529 & 366 & 0.067 & 0.027 & 529 & 367 & 0.067 & 0.027 \\
\hline 533 & 803 & 0.047 & 0.027 & 533 & 804 & 0,054 & 0.027 & 533 & 805 & 0.064 & 0.029 & 533 & 806 & 0.064 & 0.029 & 533 & 807 & 0.061 & 0.027 \\
\hline 535 & 974 & 0.062 & 0.025 & 535 & 975 & 0.062 & 0.025 & 535 & 976 & 0.062 & 0,025 & 535 & 977 & 0.066 & 0.025 & 535 & 978 & 0.066 & 0.025 \\
\hline
\end{tabular}

Sumber : SRO PT INALUM (2021)

Tabel 4. Hasil Analisa Kadar Fe dan Si di SQA

\begin{tabular}{|c|c|c|c|c|c|c|c|c|c|c|}
\hline \multirow{4}{*}{ No } & \multirow{4}{*}{ No Lot } & \multirow{4}{*}{$\begin{array}{l}\% \text { Al } \\
\text { Rata- } \\
\text { Rata }\end{array}$} & \multicolumn{8}{|c|}{ Kadar Pengotor } \\
\hline & & & \multicolumn{4}{|c|}{$\% \mathrm{Fe}$} & \multicolumn{4}{|c|}{$\% \mathrm{Si}$} \\
\hline & & & \multicolumn{4}{|c|}{ Percobaan Eksitasi } & \multicolumn{4}{|c|}{ Percobaan Eksitasi } \\
\hline & & & 1 & 2 & 3 & Rata-Rata & 1 & 2 & 3 & Rata-Rata \\
\hline 1 & 210520 & 99.92 & 0.0561 & 0.0564 & 0.0567 & 0.0564 & 0.0257 & 0.0259 & 0.0258 & 0.0258 \\
\hline 2 & 210524 & 99.93 & 0.0573 & 0.057 & 0.057 & 0.0571 & 0.0262 & 0.0258 & 0.0263 & 0.0261 \\
\hline 3 & 210528 & 99.91 & 0.0581 & 0.0588 & 0.0583 & 0.0584 & 0.026 & 0.0272 & 0.0266 & 0.0266 \\
\hline 4 & 210532 & 99.92 & 0.0591 & 0.0592 & 0.0599 & 0.0594 & 0.0264 & 0.0267 & 0.027 & 0.0267 \\
\hline 5 & 210536 & 99.91 & 0.0543 & 0.0547 & 0.0548 & 0.0546 & 0.0262 & 0.0 .265 & 0.0264 & 0.0263 \\
\hline
\end{tabular}

Sumber : SQA PT INALUM (2021) 
Journal Of Metallurgical Engineering And Processing Technology, Vol. 2, No. 1, February 2022, pp. 1-10

P-ISSN: 2723-6854, E-ISSN: 2798-1037

Dari hasil data pada Tabel 3 diatas, maka dilakukan analisa pada tiap-tiap sample di Smelter Quality Assurance (SQA), sehingga didapatkan hasil kandungan pengotor seperti Tabel 4 diatas. Dalam penelitian ini, penulis melakukan pengambilan data pada stasiun HPM Centre yang berfokus pada kadar impuritis, yaitu $\mathrm{Fe}$ dan $\mathrm{Si}$ terhadap produk ingot yang dihasilkan. Produk ingot ini kemudian akan disesuaikan dengan Standar Grade Aluminium (SGA) yang telah ditetapkan oleh PT INALUM.

Dari hasil penelitian diatas, dapat terlihat bahwa produk ingot yang dihasilkan oleh PT INALUM sudah sesuai dengan standar yang ditetapkan. Berikut merupakan analisis dari penelitian diatas.

\section{A. Standar Grade Aluminium (SGA) pada Produk Ingot PT INALUM}

Pengendalian grade produk dilakukan agar ada kesesuaian antara kadar Fe dan Si terhadap produk, sehingga produk yang dihasilkan bisa mencapai target yang telah ditetapkan di PT INALUM.

Standar pengendalian grade produk berpatokan pada Quality Standard of Aluminium Ingot (QSAI). QSAI merupakan variabel- variabel yang ditetapkan agar produk yang dihasilkan tidak menyimpang dari jadwal operasi pencetakan.

Standar pengendalian grade produk tersebut dapat dilihat pada Tabel 5 berikut.
Tabel 5. Standar Kualitas Aluminium Batangan (Ingot)

\begin{tabular}{|c|c|c|c|c|}
\hline \multicolumn{3}{|c|}{ Grade/Tingkat } & \multicolumn{3}{c|}{ Komposisi Kimia (\%) } \\
\hline PT INALUM & Class & Al & Fe & Si \\
\hline S1-A & - & $99,92 \mathrm{~min}$ & 0,04 maks & 0,04 maks \\
\hline S1-B & - & $99,90 \mathrm{~min}$ & 0,06 maks & 0,04 maks \\
\hline S1 & Special Class 1 & $99,90 \mathrm{~min}$ & 0,07 maks & 0,05 maks \\
\hline S2 & Special Class 2 & 99,85 min & 0,12 maks & 0,08 maks \\
\hline G1 & Class 1 & 99,70 min & 0,20 maks & 0,15 maks \\
\hline G2 & Class 2 & 99,50 min & 0,40 maks & 0,25 maks \\
\hline G3 & Class 3 & 99,00 min & 0,80 maks & 0,50 maks \\
\hline
\end{tabular}

Sumber : SRO PT INALUM (2021)

Apabila hasil sampel masih tetap tidak sesuai dengan standar di PT INALUM, maka dapat dilakukan beberapa cara untuk meningkatkan grade pada sampel tersebut, seperti pengadukan ulang, Pengurangan dan penambahan aluminium cair (molten), dan lain sebagainya.

\section{B. Produk Ingot yang dihasilkan PT INALUM Sudah Sesuai dengan Standar yang ditetapkan}

Dari hasil pengamatan oleh Smelter Quality Assurance (SQA) Diperoleh data yang disajikan pada Tabel 4, hasil tersebut didapatkan dari data parameter operasi pot Fe dan Si yang disajikan pada Tabel 3. Tabel 3 memaparkan tentang kandungan $\mathrm{Fe}$ dan $\mathrm{Si}$ di beberapa pot dalam jangka waktu beberapa hari, dari beberapa pot tersebut, akan dilakukan pencampuran ke dalam dapur pencetakan. Misalnya pot nomor 501, 502, 603, dicampur menjadi satu, lalu diambil sampel dan dianalisa hingga akhirnya didapatlah data seperti dalam Tabel 4.

High Purity Metal memiliki kandungan $\mathrm{Fe} \quad \leq 0,064 \%$ dan $\mathrm{Si} \leq 0,044 \%$. Berdasarkan grade yang telah ditentukan di PT INALUM, maka aluminium cair 
Journal Of Metallurgical Engineering And Processing Technology, Vol. 2, No. 1, February 2022, pp. 1-10

P-ISSN: 2723-6854, E-ISSN: 2798-1037

yang akan dicetak berdasarkan data yang ada harus sesuai dengan kemurnian dan grade yang telah ditentukan, yaitu S1-A dan S1-B. Hal tersebut dapat dilakukan karena data hasil kadar pengotor yang didapatkan memungkinakan untuk mencetak produk tersebut.

Berdasarkan data, aluminium yang memungkinkan dicetak adalah grade S1A dengan kadar aluminium $99,92 \%$ dan S1-B dengan kadar aluminium 99,90\%. Sebagai contoh untuk nomor lot 210520 dengan kemurnian 99,92\% harus dicetak untuk grade S1-A. Sementara lot nomor 210536 dengan kemurnian aluminium 99,91\% tidaklah memungkinkan dicetak untuk grade S1-A. Karena apabila dicetak untuk grade S1-A, masih terdapat zat pengotor didalamnya dan untuk grade G1 pun masih terlalu tinggi kemurniannya. Oleh sebab itu, perlu dilakukan penyesuaian dengan cara melakukan pengadukan ulang (restirring), pengurangan atau penambahan aluminium cair (molten) dan pencetakan sebagian molten.

Jika kadar besi dalam aluminium cair yang akan dicetak masih terlalu tinggi, maka aluminium yang dihasilkan akan lebih mudah terkorosi dan mudah berubah menjadi warna kuning. Sebaliknya, jika kadar silikon di dalam aluminium terlalu tinggi, maka akan menyebabkan aluminium batangan (ingot) yang dihasilkan akan menjadi keras, rapuh dan susah ditempah. Itulah beberapa pengaruh ketika kadar besi dan silikon di dalam aluminium berlebih atau tidak sesuai dengan standar yang ada.

\section{Faktor-Faktor yang Mempengaruhi Kualitas Produk Ingot pada PT INALUM}

Adapun faktor-faktor yang mempengaruhi kualitas ingot antara lain adalah :

\section{Kadar Fe dan Si}

Kadar Fe dan Si dapat berpengaruh terhadap kualitas produk, karena merupakan faktor utama penentu mutu grade yang dihasilkan. Apabila kadar Fe dan $\mathrm{Si}$ masih banyak terkandung di dalam aluminium maka haruslah dikendalikan.

Kadar Fe dan Si juga dapat berasal dari parameter operasi kondisi pot. Tingginya kadar Fe dapat disebabkan karena tingginya bath temperature yang menyebabkan bath menjadi tinggi dan bath tersebut dapat mengerosi stub anoda yang terbuat dari besi, dan akhirnya jumlah $\mathrm{Fe}$ didalam alumina menjadi meningkat. Tingginya kadar Si juga dapat disebabkan karena tingginya bath temperature sehingga dapat menyebabkan side ladge pada pot mencair dan akhirnya metal dapat mengalir ke arah dinding samping pot dan perlahan-lahan menggerus lining pot yang terbuat dari SiC. Hal tersebutlah yang menjadi salah satu penyebab tingginya kadar Fe dan Si pada molten aluminium.

\section{Flux Treatment}

Pemberian flux pada aluminium cair di furnace (dapur) harus sesuai dengan jumlah molten aluminium sehingga pemisahan oksida-oksida yang 
Journal Of Metallurgical Engineering And Processing Technology, Vol. 2, No. 1, February 2022, pp. 1-10

P-ISSN: 2723-6854, E-ISSN: 2798-1037

terkandung dalam molten tersebut dapat terpisah secara sempurna, agar aluminium ingot yang dihasilkan lebih murni. Selain itu, penggunaan waktu tahan proses fluxing juga dapat meningkatkan perolehan Aluminium, sehingga kualitas yang dihasilkan semakin baik.

\section{Kesimpulan}

Berdasarkan hasil analisa terkait kesesuaian standar grade aluminium PT INALUM dapat disimpulkan :

1. Produk yang dihasilkan oleh PT INALUM masih sesuai dengan standar aluminium yang ditetapkan, seperti hasil dari cetakan dari nomor lot 210520 dan 210524 dapat menghasilakan produk dengan grade S1-A, sedangkan hasil dari cetakan dari nomor lot 210528 dan 210536 dapat menghasilkan produk dengan grade $\mathrm{S} 1-\mathrm{B}$.

2. Semakin rendah kadar $\mathrm{Fe}$ dan $\mathrm{Si}$ didalam aluminium, maka akan semakin tinggi grade produk yang akan dihasilkan.

3. Adapun faktor yang mempengaruhi kualitas produk ingot adalah kadar Fe dan Si, serta flux treatment.

\section{Ucapan Terimakasih}

Penelitian ini dapat dengan baik berkat adanya bantuan dari berbagai pihak. Untuk itu penulis mengucapkan terimakasih kepada PT INALUM (Persero), Program Studi Teknik Melaurgi UPN "Veteran" Yogyakarta, serta berbagai pihak yang telah memberikan kerjasama yang baik dalam penelitian ini.

\section{Daftar Pustaka}

Al-mejali, J. A. dkk. (2016) 'The Role of Key Impurity Elements on the Performance of Aluminium Electrolysis - Current Efficiency and Metal Quality', The Minerals, Metals \& Materials Society, pp. 410.

Hartono Anton J; Tomojiro Kaneko. 1995. Mengenal Pelapisan Logam (elektroplating). Yogyakarta : Andi offset.

Jody, B, dkk. 1992. Recycling of Aluminium Salt Cake. London: J. Res Management and Technology.

Oxtoby, W. D. 2003. Kimia Modern. Edisi Keempat. Jilid 11. Jakarta : Erlangga Penerbit Angkasa.

Wan, H. dkk. (2020) 'Study on The Effective Distribution Coefficient of Impurity Separation in The Preparation of High Purity Aluminum', Integrative Medicine Research, 9(5), pp. 10366-10376. 